\title{
Evidence-based guidelines for fall prevention in Korea
}

\author{
Kwang-Il Kim ${ }^{1, *}$, Hye-Kyung Jung ${ }^{2,}$, Chang Oh Kim ${ }^{3}$, Soo-Kyung Kim ${ }^{4}$, Hyun-Ho Cho ${ }^{5}$, Dae Yul Kim ${ }^{6}$, \\ Yong-Chan $\mathrm{Ha}^{7}$, Sung-Hee Hwang ${ }^{8}$, Chang Won Won ${ }^{9}$, Jae-Young Lim ${ }^{10}$, Hyun Jung Kim ${ }^{11}$, Jae Gyu Kim ${ }^{12}$; \\ and The Korean Association of Internal Medicine, The Korean Geriatrics Society
}

\author{
${ }^{1}$ Department of Internal Medicine, \\ Seoul National University College \\ of Medicine, Seoul; ${ }^{2}$ Department of \\ Internal Medicine, Ewha Womans \\ University School of Medicine, \\ Seoul; ${ }^{3}$ Department of Internal \\ Medicine, Yonsei University College \\ of Medicine, Seoul; ${ }^{4}$ Division of \\ Endocrinology, Department of \\ Internal Medicine, $\mathrm{CHA}$ Bundang \\ Medical Center, CHA University, \\ Seongnam; ' ${ }^{5}$ Korean Physicians' \\ Association, Seoul; ${ }^{6}$ Department \\ of Rehabilitation Medicine, Asan \\ Medical Center, University of \\ Ulsan College of Medicine, Seoul; \\ ${ }^{7}$ Department of Orthopaedic Surgery, \\ Chung-Ang University College \\ of Medicine, Seoul; ${ }^{8}$ Department \\ of Neurology, Hallym University \\ College of Medicine, Chuncheon; \\ ${ }^{9}$ Department of Family Medicine, \\ Kyung Hee University School of \\ Medicine, Seoul; ${ }^{10}$ Department \\ of Rehabilitation, Seoul National \\ University Bundang Hospital, \\ Seongnam; ${ }^{11}$ Department of \\ Preventive Medicine, Korea \\ University College of Medicine, \\ Seoul; ${ }^{12}$ Department of Internal \\ Medicine, Chung-Ang University \\ College of Medicine, Seoul, Korea
}

Received: July 10, 2016 Accepted: July 29, 2016
Falls and fall-related injuries are common in older populations and have negative effects on quality of life and independence. Falling is also associated with increased morbidity, mortality, nursing home admission, and medical costs. Korea has experienced an extreme demographic shift with its population aging at the fastest pace among developed countries, so it is important to assess fall risks and develop interventions for high-risk populations. Guidelines for the prevention of falls were first developed by the Korean Association of Internal Medicine and the Korean Geriatrics Society. These guidelines were developed through an adaptation process as an evidence-based method; four guidelines were retrieved via systematic review and the Appraisal of Guidelines for Research and Evaluation II process, and seven recommendations were developed based on the Grades of Recommendation, Assessment, Development, and Evaluation framework. Because falls are the result of various factors, the guidelines include a multidimensional assessment and multimodal strategy. The guidelines were developed for primary physicians as well as patients and the general population. They provide detailed recommendations and concrete measures to assess risk and prevent falls among older people.

Keywords: Accidental falls; Aged; Guideline; Prevention

Correspondence to Jae Gyu Kim, M.D.

Department of Internal Medicine, Chung-Ang University College of Medicine, 84 Heukseok-ro, Dongjak-gu, Seoul 06974, Korea

Tel: $+82-2-6299-3147$

Fax: +82-2-825-7571

E-mail:jgkimd@cau.ac.kr

*These authors contributed equally to this work.

This guidelines are published as Korean version of "Evidence-based guideline for fall prevention in Korea" in "Korean J Med 2015;89:752-780" under the permission from each journal. 


\section{BACKGROUND}

Falls are the leading cause of injury among older adults and the risk of falls and subsequent fall-related injury increases with age [1]. Falls are not only associated with morbidity and mortality in older populations, but are also related to immobility, decreased quality of life, fear of falling, functional dependency, early admission to long-term care facilities, and increased medical costs [2]. Accordingly, identifying older adults at an increased risk of falls and effective fall prevention interventions have the potential to reduce fall risk among older individuals, as well as fall-related disability and medical costs [3].

In the United States, around one-third of people aged 65 years or older living in the community fall every year, and about half of those who fall do so repeatedly. Although not all falls lead to injury, about 10\% result in a major injury such as a fracture, serious soft tissue injury, or traumatic brain injury requiring medical attention [4]. In 2012, 2.4 million nonfatal falls among older adults were treated in emergency departments and more than 722,000 of these patients were hospitalized [5]. Accordingly, the direct medical costs of falls, adjusted for inflation, is estimated at $\$ 30$ billion [6].

The incidence of falls among Chinese older people is approximately half of that among Caucasian populations. A systematic literature review of studies conducted in China, Hong Kong, Singapore, and Taiwan revealed that the annual fall rate ranges from $14.7 \%$ to $34 \%$ (median, $18 \%$ ). In four prospective studies, injuries were reported by $60 \%$ to $75 \%$ of those reporting falls, with fractures accounting for $6 \%$ to $8 \%$ of all injuries [7].

Few studies have explored the prevalence and medical burden of falls among Korean older adults. One study of 351 individuals aged 65 years or older found that $42 \%$ reported at least one episode of falling in the previous 12 months, $38 \%$ of whom required either the attention of a physician or hospitalization [8]. In another study, $13 \%$ of 828 community-dwelling older Korean adults experienced falls during the last year [9]. Additionally, a questionnaire-based interview survey of 2,295 older adults living in rural communities revealed that $32 \%$ had suffered from fall-related injuries during the previous year. The direct costs of these injuries were calculated to be $596,466,000$ won (US $\$ 1=W_{1,140}$ ) and the total socioeconomic costs were estimated to be 1,054,547,000 won. When the above calculated socioeconomic cost for the 2,295 subjects is applied to the 1,067,262 Korean rural older adults in 2009, the socioeconomic costs due to fall-related injuries can be estimated as 343,614,988,000 won [10]. Accordingly, falls are one of the most common, and most important, medical problems among Korean older adults.

Previous studies have identified independent risk factors for falls or fall-related injuries. Comprehensive management of identified risks has a clinical benefit in preventing falls [11]. The greatest risk factors for falls include previous falls, strength, gait and balance impairments, visual impairment, arthritis, disability, depression, and cognitive impairment. Additionally, polypharmacy, anti-hypertension or psychotropic medications, arrhythmia, and Parkinson's disease are reportedly risk factors for falls [12-16]. The risk of falls increases with the number of risk factors, and comprehensive multifactorial assessment and risk factor interventions can decrease the risk of falls and improve the health status of older adults $[17,18]$.

\section{DEVELOPMENT OF GUIDELINES FOR FALL PREVENTION IN KOREA}

\section{The guideline committee}

The guideline committee consisted of three subcommittees. A steering committee included the president and cabinet members of the Korean Association of Internal Medicine (KAIM); it was responsible for establishing a strategy for guideline development and approving a budget. A working group was responsible for development and writing the guidelines; it included members of the Clinical Practice Guidelines Committee of KAIM, one methodology expert (a member of Korean Cochrane), and two coordinators. The guidelines were developed via multidisciplinary involvement by the KAIM and the Korean Geriatrics Society, with a focus on rehabilitation medicine, family medicine, orthopedic surgery, and neurology. The nominal group technique was applied to select the final recommendations, with a panel selected from members of the participating societies. Finally, an External Review Committee consisted of representatives of the participating societies who 


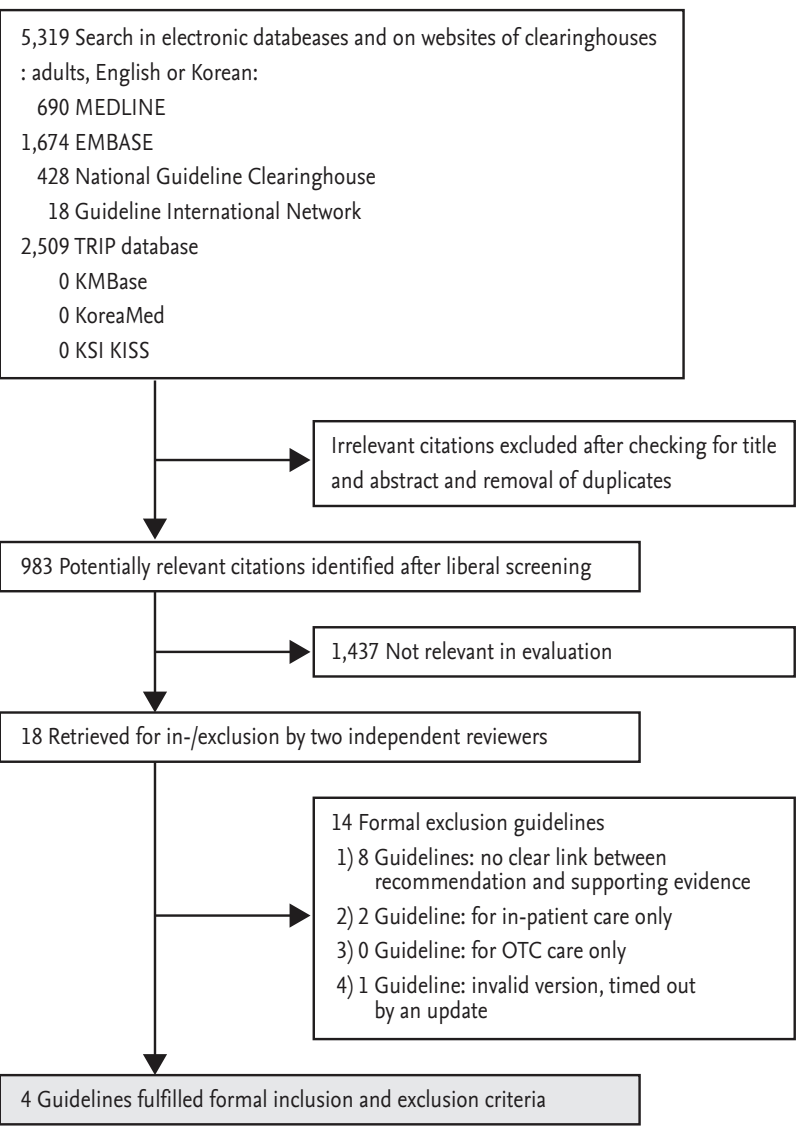

Figure 1. Flowchart of guideline selection. OTC, over-thecounter.

were not involved in the nominal group technique. The working group met 14 times, the external review group met once, and an additional seven workshops were held to engage in the ADAPTE process.

\section{The adaptation process of guidelines for fall prevention}

The guidelines were developed using an adaptation process based on evidence-based medicine. A methodology expert from Korean Cochrane (H.J.K.) participated in the development of the guidelines to help develop a scientific and standardized method. Clinical questions were designed based on PICO (population, intervention, comparison, and outcomes). A systematic review was performed to search for relevant guidelines (Fig. 1). Candidate guidelines were obtained from the following databases on February 20, 2014; MEDLINE, EMBASE, Cochrane Library, KoreaMed, Korean Medical Database, Korea Education and Research Information Ser- vice, National Guideline Clearinghouse, International Guideline Library, and Turning Research Into Practice (Appendix 1).

Target studies about guidelines published between January 1, 2009 and February 20, 2014 were reviewed. Inclusion criteria were as follows: (1) evidence-based; (2) written in Korean or English; (3) generated through expert consensus and external review; and (4) latest revised version. Guidelines for hospitalized patients, outdated versions, and guidelines that were generated using the adaptation process were excluded (Fig. 1). Two independent reviewers from the working team performed the literature review and finally four guidelines were selected. Appraisal of Guidelines for Research and Evaluation II (AGREE II) was performed for the selection of seed guidelines. Two reviewers evaluated seed guidelines based on the Korean-AGREE II developed by the Steering Committee for Clinical Practice Guideline of Korean Academy of Medical Science; this was validated through a formal consensus, and its practicality was supported through the actual guideline assessment [19]. AGREE II includes six domains (scope and purpose, stakeholder involvement, rigor of development, clarity of presentation, applicability, and editorial independence) and is comprised of 23 structured key items and two items for general assessment. Rigor of development was considered the most important selection criteria, and finally four guidelines were selected with a score greater than the scaled final score of 60\% ADAPTE (Fig. 2) [19].

Data extract tables were created to extract recommendations for each subheading with reference literatures (Appendix 2). We also performed a literature review with a de novo method for searching for updated findings for each clinical question (PICO).

The level of evidence for the planning method, quality, and consistency of each study was evaluated based on GRADE (Grades of Recommendation, Assessment, Development, and Evaluation) criteria for high overall quality of evidence across outcomes (Table 1) [20].

The first draft recommendations were made by the working group, and the final recommendations were selected using the nominal group technique. Consensus was reached by a panel of experts who were selected from the participating societies; they included experts in the fields of internal medicine, family medicine, neurology, rehabilitation medicine, and orthopedics. 

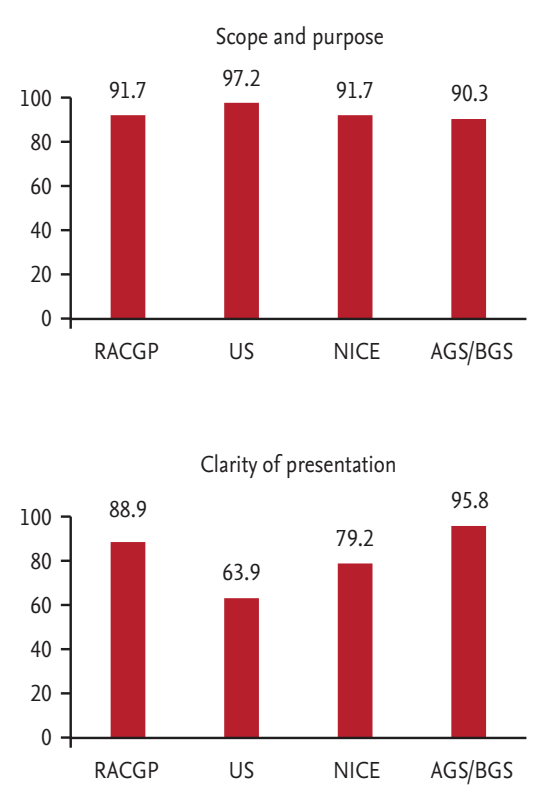
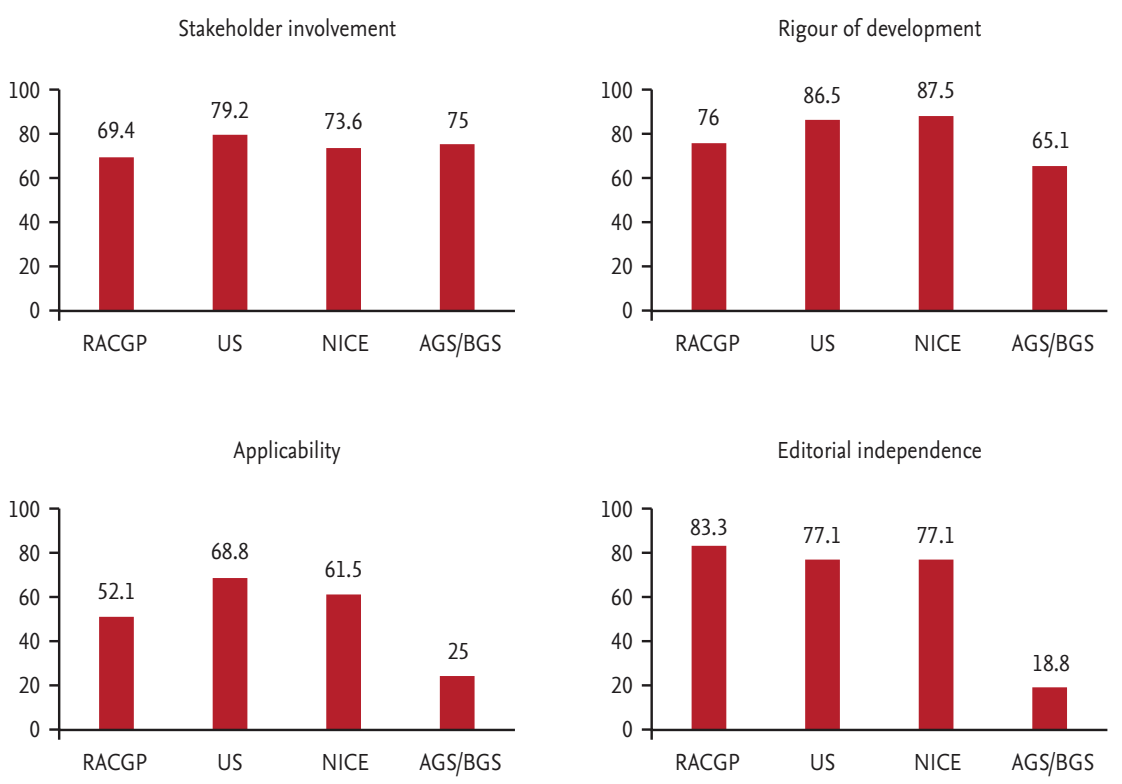

Figure 2. Evaluation of candidate guidelines based on Appraisal of Guidelines for Research and Evaluation II (AGREE II). RACGP, Royal Australian College of General Practitioners; US, United States Preventive Services Task Force; NICE, National Institute for Health and Care Excellence; AGS/BGS, American Geriatrics Society/British Geriatrics Society.

Table 1. Recommendation strength and level of evidence

\begin{tabular}{ll}
\hline Strength of recommendation & \\
\hline $\begin{array}{l}\text { Wtrong } \\
\text { Weak }\end{array}$ & $\begin{array}{l}\text { Recommendation can apply to most patients in most circumstances. } \\
\text { alternatives may be equally reasonable. }\end{array}$ \\
\hline $\begin{array}{l}\text { A. High quality } \\
\text { B. Moderate quality }\end{array}$ & $\begin{array}{l}\text { Further research is very unlikely to change our confidence in estimated effect. } \\
\text { may change the estimate. }\end{array}$ \\
$\begin{array}{ll}\text { C. Low quality } & \text { Further research is very likely to have important effects on our confidence in estimated } \\
\text { effect and is likely to change the estimate. }\end{array}$ \\
$\begin{array}{ll}\text { D. Very low quality } & \text { Any estimated effect is very uncertain. } \\
\text { E. Expert opinion } & \text { Expert opinion }\end{array}$ \\
\hline
\end{tabular}

A facilitator presented the first draft recommendations and asked the experts to brainstorm ideas; during this process, participants did not consult each other or discuss their ideas. Participants then presented each idea through a round robin process, and group discussions generated new ideas or eliminated irrelevant ideas. Final recommendations were confirmed by a voting process (Table 2) [21-24].

A peer review was performed by three reviewers who were members of the Korean Geriatrics Society (E.J.L.),
Korean Academy of Rehabilitation Medicine (J.Y.Y.), and Korean Cochrane (H.J.K.). The guidelines for fall prevention were announced publicly at an annual program for clinical medical education attended by general practitioners, gastroenterologists, and family doctors (February 15, 2015). Attendees suggested that supplementary material or tools would be helpful to evaluate the risk stratification for falls and to determine appropriate exercises for fall prevention. Therefore, these tools were added as a supplement. 
Table 2. Retrieval of recommendations in the adaptation process

\begin{tabular}{lccccc}
\hline Guidelines & $\begin{array}{c}\text { No. of key } \\
\text { recommendations }\end{array}$ & $\begin{array}{c}\text { Year of } \\
\text { publication }\end{array}$ & $\begin{array}{c}\text { Strong } \\
\text { recommendation }\end{array}$ & $\begin{array}{c}\text { Weak } \\
\text { recommendation }\end{array}$ & $\begin{array}{c}\text { Not } \\
\text { applicable }\end{array}$ \\
\hline RACGP [24] & $1,2,4,5,6,7$ & 2012 & 5 & 0 & 1 \\
US [22] & $1,2,3,5,6,7$ & 2010 & 3 & 2 & 0 \\
NICE [21] & $1,2,4,6,7$ & 2013 & 5 & 0 & 0 \\
AGS/BGS [23] & $1,2,4$ & 2010 & 3 & 0 \\
\hline
\end{tabular}

RACGP, Royal Australian College of General Practitioners; US, United States Preventive Services Task Force; NICE, National Institute for Health and Care Excellence; AGS/BGS, American Geriatrics Society/British Geriatrics Society.

The fall prevention guidelines will be updated periodically if new study outcomes become available. The KAIM financially supported the development of the guidelines and there was no other external financial support. The guideline committee of the KAIM is an independent organization, and there were no internal and external influences. All members who participated in the guideline development process had no conflicts of interest.

\section{RECOMMENDATIONS}

1. Primary care physicians should be able to identify community-dwelling elderly at an increased risk for falls by asking about a history of falls and performing gait or balance tests.

Grade of recommendation: 1

Level of evidence: E

Primary care physicians should be able to identify community-dwelling older adults at a high risk for falls. Previous studies have identified independent risk factors of falls or fall-related injuries, and fall risk increases as the number of risk factors increase. However, it is challenging to translate these findings into a strategy for primary care physicians to reliably identify older adults that require fall interventions.

Screening for falls is aimed at preventing or reducing fall risk. Any positive answer to the screening questions puts the person screened in a high-risk group that warrants further multifactorial fall risk evaluation. A history of falling is most commonly used to identify an increased risk for future falling and has generally been considered concurrently or sequentially with other key risk factors, particularly gait and balance. Previous stud- ies confirmed that fall history is the most common risk factor other than age.

Furthermore, it is simple to obtain information regarding fall history. The definition of fall history varies, with a history of at least one fall during the previous 12 months or a history of more serious falls that required medical attention. Gait and balance deficits should be evaluated in older individuals reporting a single fall as a screen for identifying individuals who may benefit from a multifactorial fall risk assessment. Older adults at higher risk of falling, as identified by screening, should be assessed for known risk factors.

According to the National Institute for Health and Care Excellence (NICE) guidelines, older people in contact with healthcare professionals should be asked routinely whether they have fallen in the past year and asked about the frequency, context, and characteristics of the falls. Older people reporting a fall or those considered at risk of falling should be observed for balance and gait deficits and considered for their ability to benefit from interventions to improve strength and balance [21].

Although the United States Preventive Services Task Force did not find evidence for frequent brief falls risk assessments, they recommended that primary care physicians could consider the following factors to identify older adults at an increased risk of falls: a history of falls, a history of mobility problems, and poor performance on the timed Get-Up-and-Go test [22].

In contrast, the American Geriatrics Society/British Geriatrics Society (AGS/BGS) guidelines recommend that all older adults under the care of a health professional should be asked at least once a year about falls, frequency of falling, and difficulties in gait or balance [23]. For individuals who screen positive for falls or fall risk, evaluation of balance and gait should be part of the multifactorial fall risk assessment. Commonly used 


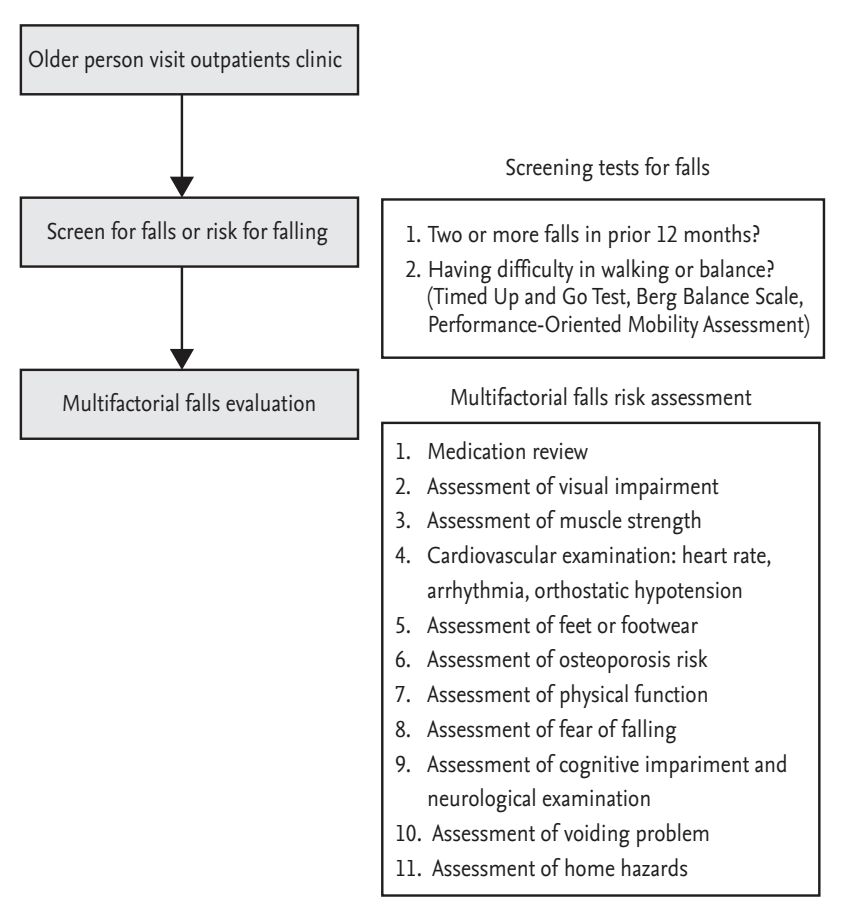

Figure 3. Algorithm of fall assessment for community-dwelling elderly.

tests of gait or balance include the Timed Up and Go test, the Berg Balance Scale, and the Performance-Oriented Mobility Assessment.

Accordingly, despite the controversy about the frequency of falls risk assessment and tools for gait and mobility evaluation, we recommend that primary care physicians should be able to identify older adults at an increased risk for falls by asking about a history of falls and performing gait or balance tests such as the Timed Up and Go test, the Berg Balance Scale, and the Performance-Oriented Mobility Assessment (Fig. 3).

2. Multifactorial fall risk assessments to identify multiple risk factors for falls can reduce the risk of falls and improve the health status of older adults at an increased risk for falls using screening tests such as fall history and abnormality in gait or balance tests. Grade of recommendation: 1

Level of evidence: $\mathrm{E}$

Comprehensive multifactorial fall assessments and interventions include assessment of multiple risk factors for falls and providing medical and social care to address factors identified during the assessment. A mul- tifactorial fall risk assessment followed by interventions to modify any identified risk factors is considered a highly effective strategy to reduce falls among older adults, as this can address the risk factors of falls, and is expected to lead to more reductions in fall risks than dealing with each risk factor separately. Multifactorial fall risk assessments are a comprehensive geriatric assessment or falls-focused assessment, generally including two or more of the following assessments: vision, gait, mobility, muscle strength, medication use, cognitive impairment, orthostatic hypotension, and environmental risks. Multifactorial assessments should be performed by a healthcare professional with appropriate skills and experience. A multifactorial fall risk assessment should be performed for community-dwelling older persons who report recurrent $(\geq 2)$ falls, difficulties with gait or balance, or who seek medical attention or present to the emergency department because of a fall [23].

According to the NICE guidelines, multifactorial assessments should include fall history, assessment of gait, balance, mobility, and muscle weakness, assessment of osteoporosis risk, assessment of the older person's perceived functional ability and fear of falling, assessment of visual impairment, assessment of cognitive impairment and neurological examination, assessment of urinary incontinence, assessment of home hazards, cardiovascular examination, and medication review.

According to the AGS/BGS guidelines, multifactorial fall risk assessments can identify factors associated with the increased risk of falling and the most appropriate interventions. They list the following components of multifactorial fall risk assessments; medication, visual acuity, neurological impairment, muscle strength, heart rate and rhythm, postural hypotension, feet and footwear, and environmental hazards [23].

Some research has reported that some combination of multifactorial fall risk assessments and interventions in a select population can provide benefits. However, the characteristics of a comprehensive multifactorial assessment and intervention have not been clearly defined, and different approaches to classification may lead to different results. Additionally, there has been statistical heterogeneity and uncertainty regarding the optimal combination of multifactorial risk assessments. Overall, these comprehensive programs seem to be complicated in a primary care setting. The USPSTF does not recom- 
mend automatically performing an in-depth multifactorial risk assessment in conjunction with comprehensive management of identified risks to prevent falls in community-dwelling older adults because the likelihood of benefit is expected to be small [25]. They recommend that clinicians should consider the balance of benefits and harms based on the circumstances of prior falls, medical comorbid conditions, and patient values in determining whether this service is appropriate in individual cases.

However, for older adults at an increased risk for falls based on screening tests such as fall history and abnormalities in gait or balance tests, multifactorial fall risk assessments and interventions can decrease the risk of falls and improve health status. Therefore, we recommend that primary care physicians perform multifactorial fall risk assessments to identify multiple risk factors for falls and improve the health status of older adults at an increased risk for falls using screening tests such as fall history and abnormalities in gait or balance tests (Fig. 3).

3. The use of combined vitamin $\mathrm{D}$ and calcium supplementation may be recommended to prevent fractures in community-dwelling elderly who are at an increased risk for falls.

Grade of recommendation: 2

Level of evidence: $\mathrm{E}$

4. Vitamin D supplementation may be recommended to prevent falls in community-dwelling older people who have low vitamin D levels.

Grade of recommendation: 2

Level of evidence: $\mathrm{E}$

Vitamin D is known to play an important role in bone tissue. The effects of vitamin $\mathrm{D}$ on intestinal absorption of calcium and bone mineralization increase bone mineral density and decrease the risk of fracture. Several lines of clinical evidence suggest the existence of a link between vitamin D and muscle or nerve function [26-28]. Vitamin D deficiency or insufficiency may result in metabolic bone disease, may increase the risk of fall, and is associated with increased risk for several health conditions including cardiometabolic diseases, infection, and autoimmune diseases [29,30]. A major reason for vitamin $\mathrm{D}$ deficiency is the lack of cutaneous production of vitamin $\mathrm{D}$ by ultraviolet due to an indoor lifestyle. Thus, vitamin D deficiency is very common in Western countries, as well as Korea [31]. Aging is also an important cause of vitamin D deficiency. Vitamin D plays an important role in elderly people at increased risk of fracture [32]. Therefore, determining whether to replenish vitamin $\mathrm{D}$ in community-dwelling older people to reduce falls or fractures is important. Many studies have analyzed the effect of vitamin D on falls and fractures in the relatively healthy elderly, but the results have been inconsistent. This could be due to potential confounders such as the characteristics of participants, vitamin $\mathrm{D}$ alone or the combination of vitamin $\mathrm{D}$ and calcium, the dosage and form of vitamin $\mathrm{D}$, treatment period of vitamin $\mathrm{D}$, or the baseline level of vitamin $\mathrm{D}$. Thus, each set of guidelines includes slightly different recommendations. The U.S. Preventive Services Task Force recommends vitamin D supplementation to prevent falls in community-dwelling adults aged 65 years or older at an increased risk for fall or older persons with proven or suspected vitamin D deficiency [22,23]. In contrast, the NICE has made no firm recommendations about the use of vitamin $\mathrm{D}$ for this indication, because of uncertainty regarding the relative contribution to fracture reduction and the dose and route of administration required [21].

The recommendations in these guidelines are derived from meta-analysis of randomized controlled trials [25,33]. A meta-analysis of 14 trials $(n=28,135)$ that evaluated the efficacy of fall prevention by supplementation with vitamin $\mathrm{D}$, either alone or with calcium co-supplementation, did not reveal statistically significant differences in rate of falls, risk of falling, or risk of fracture. Analysis limited to the elderly at higher fall risk revealed no significant differences in either rate of falls or risk of falls. However, vitamin D supplementation to older people with lower vitamin D levels significantly reduced the rate of falls (relative risk [RR], 0.57; 95\% confidence interval [CI], 0.37 to 0.89 ) and risk of falls (RR, 0.70; $95 \%$ CI, 0.56 to 0.87 ).

The effects of vitamin $\mathrm{D}$ on fractures differ depending on the characteristics of the participants and co-supplementation with calcium. Vitamin D alone produced no statistically significant reduction in hip fracture or any fracture. In contrast, administration of both vitamin D 
and calcium was associated with a significant reduction in the incidence of hip fracture $(\mathrm{RR}, 0.84 ; 95 \% \mathrm{CI}, 0.74$ to 0.96 ), non-vertebral fracture (RR, $0.86 ; 95 \% \mathrm{CI}, 0.78$ to 0.96), and any fracture (RR, 0.95; $95 \% \mathrm{CI}, 0.90$ to 0.99). In a subgroup analysis by residential status, these effects for fracture reduction were observed only in institutional residents, and were not significant in community-dwelling older people (hip fracture: RR, 0.91; 95\% CI, 0.77 to 1.09; any fracture: RR, 0.96; $95 \%$ CI, 0.91 to 1.01).

Adverse effects were not affected by vitamin $\mathrm{D}$ alone. However, there was a small increase in the risk of gastrointestinal symptoms (RR, 1.05; 95\% CI, 1.01 to 1.09) and a significant increase in renal calculi and renal disease (RR, 1.17; 95\% CI, 1.03 to 1.34), especially for vitamin $\mathrm{D}$ plus calcium supplementation. Hypercalcemia was more common in people receiving calcitriol, a vitamin $\mathrm{D}$ analogue, compared to those receiving placebo or control (RR, 4.41; 95\% CI, 2.14 to 9.09). Other systemic reviews have found an increased association of cardiovascular disease with calcium and/or vitamin D supplementation, particularly in people with a higher dietary calcium intake [34]. However, this association remains controversial. Additionally, it should be considered that daily calcium intake in the Korean population is very low $(511.0 \pm 7.0 \mathrm{mg})$ compared to that of participants enrolled in these studies [35].

In conclusion, routine supplementation of vitamin D for fall and fracture prevention for community-dwelling healthy older people is not recommended. However, vitamin D supplementation for elderly people who have lower vitamin D levels may prevent falls. Combined vitamin $\mathrm{D}$ and calcium supplementation may prevent fractures in elderly people at an increased risk of fall or fracture. A small but significant increase in gastrointestinal symptoms and renal disease is associated with vitamin $\mathrm{D}$ and/or calcium. Therefore, supplementation with vitamin $\mathrm{D}$ and/or calcium for older people living in the community should be individualized.

5. Supplementation with vitamin D may be recom-
mended for elderly people residing in long-term
care settings for the prevention of falls.
Grade of recommendation: 2
Level of evidence: A

Elderly residing in long-term care settings are at high risk for falls and fracture and are frequently deficient in vitamin D. Effective important interventions are required to reduce falls in this specific high-risk group.

Two trials were conducted: oral vitamin $\mathrm{D}_{3}$ plus calcium or oral vitamin D2 plus calcium versus a control group supplied with calcium. These two trial results both revealed a statistically significant reduction in the rate of falls $[36,37]$. However, another trial involving oral vitamin $\mathrm{D}_{3}$ (800 IU plus calcium 1,200 mg vs. matching placebo control group) revealed no significant reduction in fall risk [38]. After hospital discharge, neither vitamin D supplementation nor a home-based program of quadriceps resistance exercise improved the risk of fall compared to a control group, but patients in the exercise group were at an increased risk of musculoskeletal injury [39]. An intervention group (oral vitamin D 800 IU plus calcium 1,200 mg) was compared with a control group (calcium 1,200 mg). Although there were fewer falls in the vitamin D group, neither the mean number of falls or time to first fall differed between groups [40]. Elderly people residing in long-term care settings were randomly assigned to receive one of four doses of vita$\min \mathrm{D}(200,400,600,800 \mathrm{IU})$ or a placebo control for 5 months. The highest vitamin D group (80o IU) had fewer fallers and a lower incidence rate of falls (72\%) than the placebo control group [41]. In vitamin D2 (2.5 mg) or control groups living in care homes, no significant reductions in risk of falls or fractures were observed [42]. The effects of multivitamin supplementation, which included oral vitamin $\mathrm{D}_{3} 400 \mathrm{IU}$ and calcium $360 \mathrm{mg}$, were investigated for 6 months. There was a statistically significant reduction in rate of falls, but not in risk of falls [43].

According to the AGS/BGS Clinical Practice Guideline for Prevention of Falls in Older Persons (2010), vitamin D supplements of at least 800 IU daily should be provided to elderly people residing in long-term care settings with proven or suspected vitamin D insufficiency. Additionally, vitamin D supplements of at least 800 IU daily should be considered for elderly people residing in long-term care settings who have gait or balance disorders or who are at high risk for falls [23]. 
6. We recommend regular exercise to prevent falls and fall risk in community-dwelling elderly people.

Grade of recommendation: 1

Level of evidence: A

Elderly people who have healthy living habits, avoid sedentary lifestyles, and undergo physical exercise such as walking and other muscle exercises often maintain their health and have an independent daily life.

Falls may cause fractures, which can make it impossible for elderly people to live independently. Therefore, many studies have focused on fall prevention, including the benefits of physical exercise in improving the functional capacity of frail elderly people. Exercise programs tailored to this population are known to be effective [44].

Grahn Kronhed et al. [45] compared the fall incidence rate between two groups of people who engaged in regular exercise or did not engage in regular exercise for a period of 1 year in 2009. The regular exercise group had an average fall incidence of 0.6 , whereas the non-exercise group had an average fall incidence of 0.8 , and the difference between the two groups was statistically significant. In 2010, Clemson et al. [46] reported that those who regularly performed balance exercises and muscle strengthening had a significantly lower fall rate than those who did not. One group of elderly people living in the community performed exercises for 30 to $90 \mathrm{~min}$ utes with one 10-minute break two to three times every week. This group had more fall prevention effects than a control group [47]. One study investigated fall incidence rates among those who engage in multiple forms of exercise (muscle strengthening, balance training, endurance training, and cooperation training) compared to rates among those who do not exercise, and reported that those who engaged in multiple exercises had a significantly lower fall incidence rate. The multiple exercises improved the functional indexes of the physically weak elderly [48]. Cadore et al. [49] performed a meta-analysis of 79 studies, and found that elderly people who engage in muscle strength or endurance exercises two to three times every week have a significantly lower fall incidence rate than those who do not. Regular exercise performed at home is also effective in preventing falls [50].

The fall prevention guidelines proposed by the US/UK Geriatrics Society in 2010 strongly recommend that reg- ular and multi-layered exercises be included in fall prevention programs for the elderly [23]. The NICE guidelines recommend muscle strength and balance exercises to prevent falls among elderly people living in local communities, especially those who have experienced repeated falls, and suggested that the exercise be ordered and managed by experts [21]. USPSTF suggests that fall risk can be reduced when exercise and physical therapy are applied to high fall-risk groups of elderly patients living in local communities, and reported that this can lead to a 13\% decrease in falls [22].

In conclusion, regular exercise is required to prevent falls among community-dwelling older adults.

7. We recommend balance training, strengthening exercise, aerobic exercise, or resistance exercise to prevent falls and fall risk among community-dwelling elderly.

Grade of recommendation: 1

Level of evidence: A

Regular exercise can prevent falls among community-dwelling elderly. Exercise among community-dwelling elderly is classified as group-based exercise or homebased exercise. Home-based exercise has advantages such as being less expensive and allowing long-term performance. Regular exercise in home-based programs improves physical function, prevents falls, maintains bone mineral density, and is feasible within daily life. Strengthening exercises and balance training in homebased exercise decreases the risk of fall [51,52]. However, home-based programs also have limitations in terms of lower compliance and being less effective than groupbased exercise [53,54].

Static and dynamic balancing exercises can be used to improve balance among community-dwelling elderly. Balance exercises may include sit-to-stands, tandem standing, tandem gaiting, unipedal standing, knee bends, change in direction, catching/throwing a ball, and tai-chi [48,55-58].

Strengthening exercises may include ankle cuff weights [57], thera bands [59], and various resistance exercises [6o]. They may also include walking, exercise on stationary cycles, and knee and hip extensions performed with a oneleg press in a sitting position. Aerobic and resistive exercises include hip abduction and extension in a standing 
position [61]. The appropriate amount and type of exercise depends on individual health status. In conclusion, community-dwelling elderly persons at high risk of falling should undergo balance training, strengthening exercises, aerobic exercises, and/or resistance exercises.

\section{Conflict of interest}

No potential conflict of interest relevant to this article was reported.

\section{REFERENCES}

1. Kannus P, Sievanen H, Palvanen M, Jarvinen T, Parkkari J. Prevention of falls and consequent injuries in elderly people. Lancet 2005;366:1885-1893.

2. Tinetti ME, Williams CS. The effect of falls and fall injuries on functioning in community-dwelling older persons. J Gerontol A Biol Sci Med Sci 1998;53:M112-M119.

3. Kannus P, Parkkari J, Koskinen S, et al. Fall-induced injuries and deaths among older adults. JAMA 1999;281:18951899 .

4. Tinetti ME, Speechley M, Ginter SF. Risk factors for falls among elderly persons living in the community. N Engl J Med 1988;319:1701-1707.

5. Centers for Disease Control and Prevention, National Center for Injury Prevention and Control. Web-based Injury Statistics Query and Reporting System (WISQARS) [Internet]. Atlanta (GA): Centers for Disease Control and Prevention, 2016 [cited 2016 Dec 20]. Available from: https://www.cdc.gov/injury/wisqars.

6. Stevens JA, Corso PS, Finkelstein EA, Miller TR. The costs of fatal and non-fatal falls among older adults. Inj Prev 2006;12:290-295.

7. Kwan MM, Close JC, Wong AK, Lord SR. Falls incidence, risk factors, and consequences in Chinese older people: a systematic review. J Am Geriatr Soc 2011;59:536-543.

8. Sohng KY, Moon JS, Song HH, Lee KS, Kim YS. Risk factors for falls among the community-dwelling elderly in Korea. Taehan Kanho Hakhoe Chi 2004;34:1483-1490.

9. Lim JY, Park WB, Oh MK, Kang EK, Paik NJ. Falls in a proportional region population in Korean elderly: Incidence, consequences, and risk factors. J Korean Geriatr Soc 2010;14:8-17.

10. Lee SG, Kam S. Incidence and estimation of socioeconomic costs of falls in the rural elderly population. J Ko- rean Geriatr Soc 2011;15:8-19.

11. Tinetti ME, Kumar C. The patient who falls: "It's always a trade-off". JAMA 2010;303:258-266.

12. Tinetti ME, Han L, Lee DS, et al. Antihypertensive medications and serious fall injuries in a nationally representative sample of older adults. JAMA Intern Med 2014;174:588-595.

13. Leipzig RM, Cumming RG, Tinetti ME. Drugs and falls in older people: a systematic review and meta-analysis. II. Cardiac and analgesic drugs. J Am Geriatr Soc 1999;47:4050.

14. Leipzig RM, Cumming RG, Tinetti ME. Drugs and falls in older people: a systematic review and meta-analysis: I. Psychotropic drugs. J Am Geriatr Soc 1999;47:30-39.

15. Kerr GK, Worringham CJ, Cole MH, Lacherez PF, Wood JM, Silburn PA. Predictors of future falls in Parkinson disease. Neurology 2010;75:116-124.

16. Lim JY, Jung SH, Kim WS, Paik NJ. Incidence and risk factors of poststroke falls after discharge from inpatient rehabilitation. PM R 2012;4:945-953.

17. Tinetti ME, Baker DI, McAvay G, et al. A multifactorial intervention to reduce the risk of falling among elderly people living in the community. N Engl J Med 1994;331:821-827.

18. Tinetti ME, Baker DI, King M, et al. Effect of dissemination of evidence in reducing injuries from falls. N Engl J Med 2008;359:252-261.

19. Ministry of Health \& Welfare; Korean Academy of Medical Science. Korean appraisal of guidelines for research \& evaluation II [Internet]. Seoul (KR): Korean Medical Guideline Information Center, 2013 [cited 2016 Dec 20]. Available from: http://www.agreetrust.org/wp-content/ uploads/2013/06/AGREE_II_Korean.pdf.

20. Guyatt GH, Cook DJ, Jaeschke R, Pauker SG, Schunemann HJ. Grades of recommendation for antithrombotic agents: American College of Chest Physicians Evidence-Based Clinical Practice Guidelines (8th Edition). Chest 2008;133(6 Suppl):123S-131S.

21. Centre for Clinical Practice at NICE (UK). Falls: assessment and prevention of falls in older people [Internet]. London (UK): National Institute for Health and Care Excellence, c2016 [cited 2016 Dec 20]. Available from: https:// www.nice.org.uk/guidance/cg161.

22. Moyer VA; U.S. Preventive Services Task Force. Prevention of falls in community-dwelling older adults: U.S. Preventive Services Task Force recommendation statement. Ann 
Intern Med 2012;157:197-204.

23. Panel on Prevention of Falls in Older Persons, American Geriatrics Society and British Geriatrics Society. Summary of the Updated American Geriatrics Society/ British Geriatrics Society clinical practice guideline for prevention of falls in older persons. J Am Geriatr Soc 2011;59:148-157.

24. Royal Australian College of General Practitioners (RACGP). Preventive activities in older age. In: Ackermann E, Harris M; Royal Australian College of General Practitioners, eds. Guidelines for Preventive Activities in General Practice. 8th ed. East Melbourne: The Royal Australian College of General Practitioners, 2012.

25. Gillespie LD, Robertson MC, Gillespie WJ, et al. Interventions for preventing falls in older people living in the community. Cochrane Database Syst Rev 2012;(9):CDoo7146.

26. Dawson-Hughes B, Harris SS, Krall EA, Dallal GE. Effect of calcium and vitamin D supplementation on bone density in men and women 65 years of age or older. N Engl J Med 1997;337:670-676.

27. Ceglia L. Vitamin D and skeletal muscle tissue and function. Mol Aspects Med 2008;29:407-414.

28. Annweiler C, Schott AM, Berrut G, et al. Vitamin D and ageing: neurological issues. Neuropsychobiology 2010;62:139-150.

29. Lagishetty V, Liu NQ, Hewison M. Vitamin D metabolism and innate immunity. Mol Cell Endocrinol 2011;347:97105 .

30. Vaidya A. Vitamin D and cardio-metabolic disease. Metabolism 2013;62:1697-1699.

31. Choi HS, Oh HJ, Choi H, et al. Vitamin D insufficiency in Korea: a greater threat to younger generation: the Korea National Health and Nutrition Examination Survey (KNHANES) 2008. J Clin Endocrinol Metab 2011;96:643-651.

32. MacLaughlin J, Holick MF. Aging decreases the capacity of human skin to produce vitamin D3. J Clin Invest 1985;76:1536-1538.

33. Avenell A, Mak JC, O'Connell D. Vitamin D and vitamin $\mathrm{D}$ analogues for preventing fractures in post-menopausal women and older men. Cochrane Database Syst Rev 2014;(4):CDooo227.

34. Bolland MJ, Grey A, Avenell A, Gamble GD, Reid IR. Calcium supplements with or without vitamin $\mathrm{D}$ and risk of cardiovascular events: reanalysis of the Women's Health Initiative limited access dataset and meta-analysis. BMJ 2011;342:d2040.

35. Korea National Health \& Nutrition Examination Survey. Korea National Health And Nutrition Examination Survey (KNHANES VI-1). Korea Health Statistics 2013. Cheongju: Korea Centers for Disease Control and Prevention, 2014.

36. Bischoff HA, Stahelin HB, Dick W, et al. Effects of vitamin $\mathrm{D}$ and calcium supplementation on falls: a randomized controlled trial. J Bone Miner Res 2003;18:343-351.

37. Flicker L, MacInnis RJ, Stein MS, et al. Should older people in residential care receive vitamin $\mathrm{D}$ to prevent falls? Results of a randomized trial. J Am Geriatr Soc 2005:53:1881-1888.

38. Chapuy MC, Pamphile R, Paris E, et al. Combined calcium and vitamin $\mathrm{D}_{3}$ supplementation in elderly women: confirmation of reversal of secondary hyperparathyroidism and hip fracture risk: the Decalyos II study. Osteoporos Int 2002;13:257-264.

39. Latham NK, Anderson CS, Lee A, et al. A randomized, controlled trial of quadriceps resistance exercise and vitamin D in frail older people: the Frailty Interventions Trial in Elderly Subjects (FITNESS). J Am Geriatr Soc 2003;51:291-299.

40. Burleigh E, McColl J, Potter J. Does vitamin D stop inpatients falling? A randomised controlled trial. Age Ageing 2007;36:507-513.

41. Broe KE, Chen TC, Weinberg J, Bischoff-Ferrari HA, Holick MF, Kiel DP. A higher dose of vitamin d reduces the risk of falls in nursing home residents: a randomized, multiple-dose study. J Am Geriatr Soc 2007;55:234-239.

42. Law M, Withers H, Morris J, Anderson F. Vitamin D supplementation and the prevention of fractures and falls: results of a randomised trial in elderly people in residential accommodation. Age Ageing 2006;35:482-486.

43. Grieger JA, Nowson CA, Jarman HF, Malon R, Ackland LM. Multivitamin supplementation improves nutritional status and bone quality in aged care residents. Eur J Clin Nutr 2009;63:558-565.

44. Freiberger E, Haberle L, Spirduso WW, Zijlstra GA. Long-term effects of three multicomponent exercise interventions on physical performance and fall-related psychological outcomes in community-dwelling older adults: a randomized controlled trial. J Am Geriatr Soc 2012;60:437-446.

45. Grahn Kronhed AC, Hallberg I, Odkvist L, Moller M. Effect of training on health-related quality of life, pain and falls in osteoporotic women. Adv Physiother 2009;11:154- 
165 .

46. Clemson L, Singh MF, Bundy A, et al. LiFE pilot study: a randomised trial of balance and strength training embedded in daily life activity to reduce falls in older adults. Aust Occup Ther J 2010;57:42-50.

47. Lord SR, Castell S, Corcoran J, et al. The effect of group exercise on physical functioning and falls in frail older people living in retirement villages: a randomized, controlled trial. J Am Geriatr Soc 2003;51:1685-1692.

48. Barnett A, Smith B, Lord SR, Williams M, Baumand A. Community-based group exercise improves balance and reduces falls in at-risk older people: a randomised controlled trial. Age Ageing 2003;32:407-414.

49. Cadore EL, Rodriguez-Manas L, Sinclair A, Izquierdo M. Effects of different exercise interventions on risk of falls, gait ability, and balance in physically frail older adults: a systematic review. Rejuvenation Res 2013;16:105-114.

50. Suzuki T, Kim H, Yoshida H, Ishizaki T. Randomized controlled trial of exercise intervention for the prevention of falls in community-dwelling elderly Japanese women. J Bone Miner Metab 2004;22:602-611.

51. Day L, Fildes B, Gordon I, Fitzharris M, Flamer H, Lord S. Randomised factorial trial of falls prevention among older people living in their own homes. BMJ 2002;325:128.

52. Kamide N, Shiba Y, Shibata H. Effects on balance, falls, and bone mineral density of a home-based exercise program without home visits in community-dwelling elderly women: a randomized controlled trial. J Physiol Anthropol 2009;28:115-122.

53. van der Bij AK, Laurant MG, Wensing M. Effectiveness of physical activity interventions for older adults: a review. Am J Prev Med 2002;22:120-133.

54. Mayoux-Benhamou MA, Roux C, Perraud A, Fermanian J, Rahali-Kachlouf H, Revel M. Predictors of compliance with a home-based exercise program added to usual medical care in preventing postmenopausal osteoporosis: an 18-month prospective study. Osteoporos Int 2005;16:325-331.

55. Wolf SL, Barnhart HX, Kutner NG, McNeely E, Coogler C, $\mathrm{Xu}$ T. Reducing frailty and falls in older persons: an investigation of Tai Chi and computerized balance training. Atlanta FICSIT Group. Frailty and Injuries: Cooperative Studies of Intervention Techniques. J Am Geriatr Soc 1996;44:489-497.

56. Wolf SL, Barnhart HX, Ellison GL, Coogler CE. The effect of Tai Chi Quan and computerized balance training on postural stability in older subjects. Atlanta FICSIT Group. Frailty and Injuries: Cooperative Studies on Intervention Techniques. Phys Ther 1997;77:371-381.

57. Gardner MM, Buchner DM, Robertson MC, Campbell AJ. Practical implementation of an exercise-based falls prevention programme. Age Ageing 2001;30:77-83.

58. Iwamoto J, Suzuki H, Tanaka K, et al. Preventative effect of exercise against falls in the elderly: a randomized controlled trial. Osteoporos Int 2009;20:1233-1240.

59. Bunout D, Barrera G, Avendano M, et al. Results of a community-based weight-bearing resistance training programme for healthy Chilean elderly subjects. Age Ageing 2005;34:80-83.

6o. Yamada M, Tanaka B, Nagai K, Aoyama T, Ichihashi N. Trail-walking exercise and fall risk factors in community-dwelling older adults: preliminary results of a randomized controlled trial. J Am Geriatr Soc 2010;58:19461951.

61. Hauer K, Rost B, Rutschle K, et al. Exercise training for rehabilitation and secondary prevention of falls in geriatric patients with a history of injurious falls. J Am Geriatr Soc 2001;49:10-20. 
Appendix 1. Key words for systematic review

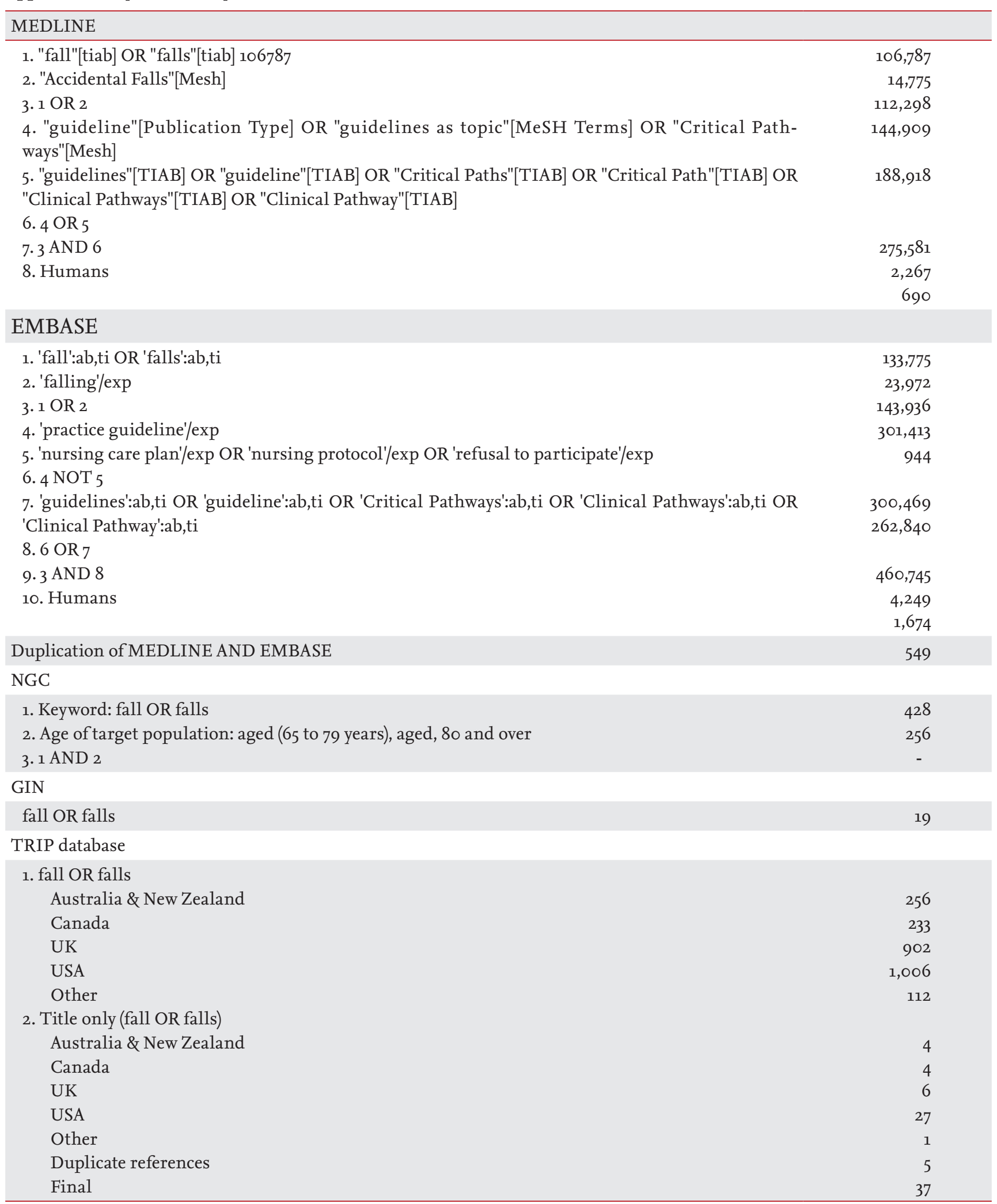

NGC, National Guideline Clearinghouse; GIN, Guidelines International Network; TRIP, Turning Research Into Practice. 


\section{Appendix 2. Data extraction form}

\begin{tabular}{|c|c|c|c|c|c|c|}
\hline Recommendation & $\mathrm{SR} / \mathrm{MA}$ & RCT & NRCS & $\begin{array}{l}\text { Consen- } \\
\text { sus }\end{array}$ & $\begin{array}{l}\text { Expert } \\
\text { opinion }\end{array}$ & $\begin{array}{l}\text { Level of } \\
\text { evidence }\end{array}$ \\
\hline $\begin{array}{l}\text { 1. Primary care physicians should be able to identify } \\
\text { community-dwelling elderly at an increased risk for falls by } \\
\text { asking about a history of falls and performing gait or balance } \\
\text { tests. }\end{array}$ & o & o & 0 & 0 & 3 & $\mathrm{E}$ \\
\hline $\begin{array}{l}\text { 2. Multifactorial fall risk assessments to identify multiple risk } \\
\text { factors for falls can reduce the risk of falls and improve the } \\
\text { health status of older adults at an increased risk for falls. }\end{array}$ & 0 & 1 & o & & 3 & $\mathrm{E}$ \\
\hline $\begin{array}{l}\text { 3. The use of combined vitamin } \mathrm{D} \text { and calcium supplementation } \\
\text { may be recommended to prevent fractures in community- } \\
\text { dwelling elderly who are at an increased risk for falls. }\end{array}$ & 2 & 2 & $\mathrm{o}$ & $\mathrm{o}$ & o & $\mathrm{E}$ \\
\hline $\begin{array}{l}\text { 4. Vitamin D supplementation may be recommended to prevent } \\
\text { falls in community-dwelling older people who have low vitamin } \\
\text { D levels. }\end{array}$ & 2 & o & 0 & o & o & $\mathrm{B}$ \\
\hline $\begin{array}{l}\text { 5. Supplementation with vitamin } \mathrm{D} \text { may be recommended for } \\
\text { elderly people residing in long-term care settings for the } \\
\text { prevention of falls. }\end{array}$ & & 5 & & & & A \\
\hline $\begin{array}{l}\text { 6. We recommend regular exercise to prevent falls and fall risk in } \\
\text { community-dwelling elderly people. }\end{array}$ & 6 & 11 & & 0 & o & A \\
\hline $\begin{array}{l}\text { 7. We recommend balance training, strengthening exercise, } \\
\text { aerobic exercise, or resistance exercise to prevent falls and fall } \\
\text { risk among community-dwelling elderly. }\end{array}$ & 0 & 26 & & 0 & o & $\mathrm{A}$ \\
\hline
\end{tabular}

Detailed reports can be identified in Korean version of "Evidence-based guideline for fall prevention in Korea" in "Korean J Med 2015;89:752-780.

SR/MA, systemic review/meta-analysis; RCT, randomized controlled trial; NRCS, non-randomized comparative study. 